Revue

Revue de l'histoire des religions

de Ihistoire des religions

Pierre LOMBARD, Les Quatre Livres des Sentences, Deuxième Livre. Introduction, traduction, notes et tables par Marc OZILOU

Paris, Les Éditions du Cerf (« Sagesses chrétiennes »), 2013

Camille Rouxpetel

\title{
OpenEdition
}

Journals

Édition électronique

URL : http://journals.openedition.org/rhr/8517

DOI : $10.4000 /$ rhr.8517

ISSN : 2105-2573

Éditeur

Armand Colin

Édition imprimée

Date de publication : 1 mars 2016

Pagination : 127-128

ISBN : 978-2-200-93059-2

ISSN : 0035-1423

Référence électronique

Camille Rouxpetel, « Pierre Lombard, Les Quatre Livres des Sentences, Deuxième Livre. Introduction, traduction, notes et tables par Marc ozıLou ", Revue de l'histoire des religions [En ligne], 1 | 2016, mis en ligne le 05 avril 2016, consulté le 23 septembre 2020. URL : http://journals.openedition.org/rhr/8517 DOI : https://doi.org/10.4000/rhr.8517

Ce document a été généré automatiquement le 23 septembre 2020 .

Tous droits réservés 


\section{Pierre LOMBARD, Les Quatre Livres des Sentences, Deuxième Livre. Introduction, traduction, notes et tables par Marc OZILOU}

Paris, Les Éditions du Cerf (« Sagesses chrétiennes »), 2013

\section{Camille Rouxpetel}

\section{RÉFÉRENCE}

Pierre LOMBARD, Les Quatre Livres des Sentences, Deuxième Livre. Introduction, traduction, notes et tables par Marc ozILou, Paris, Les Éditions du Cerf (« Sagesses chrétiennes »), 2013, 19,5 cm, 507 p., $45 €$, ISBN 978-2-204-09852-6.

1 Après la publication, entre 2007 et 2010, de la traduction anglaise du Livre des Sentences par Giulio Silano (Toronto, Pontifical Institute of Medieval Studies), cette traduction française de Marc Ozilou a le mérite de rendre accessible à un lectorat francophone, non latiniste, une œuvre essentielle à la compréhension de l'évolution de la théologie et de l'exégèse biblique à partir du XII ${ }^{\mathrm{e}}$ siècle, tant cet ouvrage, par les discussions et les commentaires qu'il a suscités, a été fondateur «dans la constitution d'une exégèse scientifique, un peu moins d'un siècle après sa rédaction » (Gilbert Dahan, «Le Livre des Sentences et l'exégèse biblique ", Pietro Lombardo: atti del XLIII Convegno storico internazionale, Todi, 8-10 ottobre 2006, Spolète, 2007, p. 333-360, ici p. 333). L'ouvrage se présente en deux parties, une introduction précédant la traduction proprement dite, fondée sur l'édition de Grottaferrata, publiée en deux volumes, respectivement en 1971 pour les livres I et II et en 1981 pour les livres III et IV.

2 Après une introduction au premier livre publié en 2012, consacrée à l'«aspect historique ", l'introduction au deuxième livre, qui se présente comme un commentaire suivi du début de la Genèse, de la Création à la Chute, « veut davantage insister sur son 
aspect littéraire » (p. 7). Se livrant essentiellement à une entreprise de traduction, il est néanmoins dommage que l'auteur n'apporte pas de précision sur ses choix et sur les éventuelles difficultés rencontrées. On peut également déplorer l'absence d'une introduction critique spécifiquement centrée sur l'apport de ce deuxième livre dans l'économie des Sentences et dans la compréhension de ce que pouvaient être l'exégèse et la théologie dans la première moitié du $\mathrm{XII}^{\mathrm{e}}$ siècle - manquent à tout le moins des indications bibliographiques conséquentes. Toutefois, ces pages permettent de bien en saisir « l'architecture extérieure ». L'auteur donne successivement le plan général puis détaillé (p.13-25), avant d'en fournir un résumé organisé selon les "concepts» mobilisés par le Lombard, dans leur ordre d'apparition (p. 32-59). Enfin, Marc Ozilou reproduit utilement les têtes de chapitres avant la traduction de la première distinction, suivant ici l'édition de Grottaferrata qui reprend les distinctions effectuées par Alexandre de Halès, sur lesquelles se sont fondés les commentateurs des siècles suivants. En revanche, l'on ne peut qu'être intéressé par les éléments fournis par le traducteur sur la «rhétorique»: ces quelques indications simples et claires sont précieuses pour le lecteur non spécialiste, sinon sur leur usage, du moins sur la nature des sources utilisées par Pierre Lombard, ainsi que sur son recours à la ratio.

Ces indications sont complétées dans le corps du texte par un appareil de notes conséquent, fondé sur l'édition critique de Grottaferrata (identifiant pour l'essentiel les citations de Pierre Lombard), et par l'élaboration de deux index, l'un biblique, l'autre des auteurs anciens et médiévaux. Notes et index matérialisent avec profit la prégnance de l'Écriture et l'importance des autorités patristiques et de la Glose ordinaire. Après leur identification, une lecture attentive permet de discriminer plusieurs usages des citations bibliques et patristiques, comme auctoritates, sur le modèle des testimonia ou de l'exemplum biblique, ou comme point de départ d'un travail d'interprétation du message biblique. Notes et index guident ainsi le lecteur dans la compréhension des logiques propres à l'exégèse biblique et à la théologie dans les Sentences d'une part, et dans les relations entretenues entre celles-ci et la leçon biblique d'autre part. Si le propos de Marc Ozilou n'est pas d'apporter de nouveaux éléments de connaissance ou de commentaire aux spécialistes du sujet, on ne peut que se féliciter de la mise à disposition d'une traduction française du Livre des Sentences à destination d'un public, sinon spécialiste, du moins cultivé, s'intéressant à l'histoire culturelle et religieuse de l'Occident chrétien et souhaitant parfaire sa connaissance d'un ouvrage essentiel en soi comme pour les nombreux commentaires dont il fut l'objet jusque dans les derniers siècles du Moyen Âge.

\section{AUTEURS}

\section{CAMILLE ROUXPETEL}

École française de Rome. 